\title{
The association of variants in PNPLA3 and GRP78 and the risk of developing hepatocellular carcinoma in an Italian population
}

\author{
Daniele Balasus ${ }^{1, *}$, Michael Way, ${ }^{2,}$, Caterina Fusilli ${ }^{3}$ Tommaso Mazza ${ }^{3}$, Marsha \\ Y. Morgan ${ }^{2}$, Melchiorre Cervello ${ }^{4}$, Lydia Giannitrapani ${ }^{1}$, Maurizio Soresi ${ }^{1}$, Rosalia \\ Agliastro $^{5}$, Manlio Vinciguerra ${ }^{2,6}$, Giuseppe Montalto ${ }^{1,4}$ \\ ${ }^{1}$ Biomedical Department of Internal Medicine and Medical Specialties, University of Palermo, Palermo, Italy \\ ${ }^{2}$ Institute for Liver \& Digestive Health, Division of Medicine, Royal Free Campus, University College London, London, UK \\ ${ }^{3}$ IRCCS Casa Sollievo della Sofferenza, Bioinformatics Unit, San Giovanni Rotondo (FG), Italy \\ ${ }^{4}$ Institute of Biomedicine and Molecular Immunology, National Research Council (C.N.R.), Palermo, Italy \\ ${ }^{5}$ Immunohematology and Transfusion Medicine Unit, "Civico" Reference Regional Hospital, Palermo, Italy \\ ${ }^{6}$ Center for Translational Medicine (CTM), International Clinical Research Center (ICRC), St. Anne's University Hospital, Brno, \\ Czech Republic \\ *These authors have contributed equally to this work \\ Correspondence to: Daniele Balasus, email: d77balasus@gmail.com \\ Manlio Vinciguerra, email: m.vinciguerra@ucl.ac.uk
}

Keywords: hepatocellular carcinoma, hepatitis C virus, single nucleotide polymorphisms, risk factors, genetic variants

Received: July 26, 2016

Accepted: November 07, 2016

Published: November 24, 2016

\section{ABSTRACT}

Hepatocellular carcinoma (HCC) has one of the worst prognoses amongst all malignancies. It commonly arises in patients with established liver disease and the diagnosis often occurs at an advanced stage. Genetic variations, such as single nucleotide polymorphisms (SNPs), may alter disease risk and thus may have use as predictive markers of disease outcome. The aims of this study were (i) to assess the association of two SNPs, rs430397 in GRP78 and rs738409 in PNPLA3 with the risk of developing HCC in a Sicilian association cohort and, (ii) to use a machine learning technique to establish a predictive combinatorial phenotypic model for HCC including rs430397 and rs738409 genotypes and clinical and laboratory attributes. The controls comprised of 304 healthy subjects while the cases comprised of 170 HCC patients the majority of whom had hepatitis C (HCV)-related cirrhosis. Significant associations were identified between the risk of developing HCC and both rs430397 $(p=0.0095)$ and $r s 738409(p=0.0063)$. The association between rs738409 and HCC was significantly stronger in the HCV positive cases. In the best prediction model, represented graphically by a decision tree with an acceptable misclassification rate of $17.0 \%$, the A/A and G/A genotypes of the rs430397 variant were fixed and combined with the three rs738409 genotypes; the attributes were age, sex and alcohol. These results demonstrate significant associations between both rs430397 and rs738409 and HCC development in a Sicilian cohort. The combinatorial predictive model developed to include these genetic variants may, if validated in independent cohorts, allow for earlier diagnosis of HCC.

\section{INTRODUCTION}

Hepatocellular carcinoma (HCC) is the most common of the primary liver cancers. It is the fifth most common malignancy worldwide and the third most frequent cause of cancer-related deaths [1-3]. The epidemiology of
HCC is complex reflecting, to a large extent, differences in levels of exposure to known predisposing factors such as the presence of cirrhosis, chronic infection with hepatitis B virus (HBV) and hepatitis C virus $(\mathrm{HCV})$ and environmental toxin exposure. Prevalence rates are 16 to 32 times higher in economically less- 
developed countries such as sub-Saharan Africa South-east Asia and China [4]. In Eastern Asia the major risk factor for HCC is infection with hepatitis $\mathrm{B}[5,6]$, whereas in Northern and Western Europe excess alcohol consumption and infection with $\mathrm{HCV}$ are the main antecedents [3]. In developed countries HCC develops most frequently in patients with established cirrhosis whereas elsewhere HCC may arise in patients with chronic $\mathrm{HBV}$ and $\mathrm{HCV}$ infection at a pre-cirrhotic stage $[7,8]$. There are also data to support a role for tobacco smoking, diabetes and obesity as risk factors or risk co-factors for the development of HCC [9]. Finally there are important gender differences in HCC prevalence; men are at two- to five-fold increased risk of developing this malignancy than women, depending on geographic area, which most likely reflect their increased exposures to known risk factors [1].

As the epidemiology of HCC has become better understood, so has the fact that only 5 to $20 \%$ of the populations potentially at risk actually develop HCC. Interest has, therefore, turned to the identification of the factors responsible for the differences in individual susceptibility; in particular the role of genetic variation. Two of the most notable genetic findings to date have been the association between the Single Nucleotide Polymorphisms (SNP), rs430397 and rs738409, with HCC risk. The rs430397 variant in glucose regulated protein 78 (GRP78 also known as HSPA5) has been associated with $\mathrm{HCC}$ and cirrhosis risk in Chinese populations with HBV infection $[10,11]$. There is considerable functional and genetic evidence implicating the GRP78 protein in mechanisms of HCC carcinogenesis $[12,13]$ and indeed in malignancies at other sites $[14,15]$. The rs738409 variant in patatin-like phospholipase domain-containing 3 (PNPLA3) has been identified as conferring a significant risk for developing cirrhosis in relation to non-alcohol-related fatty liver disease [16] and alcohol-related liver disease [17]. The rs738409 variant not only contributes to liver injury, but also to the risk of development of subsequent HCC [18, 19]. The nature of the association between the rs 738409 variant in $\mathrm{HCV}$-related HCC is less well characterized than in $\mathrm{HCC}$ of other aetiologies possibly because there is significant heterogeneity in the study populations in which this variant has been studied [20].

Variants in GRP78 and PNPLA3 have been associated with $\mathrm{HCC}$ risk in populations of diverse ancestry and with HCC of diverse aetiology. It is not known, however what proportion of the variance in HCC risk can be attributed to genetic factors in Southern European populations in whom the main risk factor for the development of HCC is chronic HCV infection and the incidence is rising [9]. Further, it is widely recognized that $\mathrm{HCC}$ risk prediction in chronic liver disease will have clinical utility in guiding evidence-based decisions about patient management [21] but it is unclear as to whether genetic information could improve the predictive models. Machine learning techniques have the potential to improve the accuracy of predictive models using genetic data [22]. A number of machine learning techniques have been developed, but all make use of computer algorithms that improve predictive accuracy with experience. Decision tree algorithms in particular are a well-established technique, which are useful for exploratory analysis and model visualisation.

The aims of the present study were therefore to assess, whether (i) two genetic variants in PNPLA3 and $G R P 78$ are associated with the risk of developing HCC in a Sicilian population, and (ii) whether inclusion of genotypic information would contribute to a predictive model designed to stratify patients by HCC risk.

\section{RESULTS}

\section{Cohort characteristics}

The cases were significantly older than the healthy controls (mean $\pm 1 \mathrm{SD}$ age $70.2 \pm 8.0$ vs. $56.6 \pm 8.1$ years; $\left.\mathrm{p}=2.2 \times 10^{-16}\right)$ and comprised of proportionately fewer men $(70.4 \%$ vs. $58.2 \%, p=0.007)$ (Table 1$)$. All but one of the cases had established cirrhosis; in the majority chronic HCV infection was the aetiological agent (Table 1). A small proportion of patients $(n=12 ; 7 \%)$, had marked steatosis in addition to cirrhosis. Up to $40 \%$ of the cases had experienced a major complication of chronic liver disease; and the majority had features of hepatocellular dysfunction with poor synthetic and excretory function (Table 2). Features of cirrhosis were evident on imaging in all included cases; ultrasonography was the modality most frequently employed (Table 2). The diagnosis of HCC was made in the majority on the basis of multimodal imaging; less than a quarter of patients had an elevated serum alphafetoprotein level (Table 3).

\section{Genotyping quality}

The genotyping success rate was greater than 95\% for both variants, with genotype distributions showing no evidence for deviation from Hardy-Weinberg equilibrium in controls ( $p>0.05)$. The minor and major allele designations of both rs430397 and rs738409 were generally similar in this Sicilian ancestry cohort to those in reference Europeans ancestry groups [23]; however, the minor allele (G) of rs738409 was noticeably more frequent in Sicilian controls than in European reference populations.

\section{GRP78 and PNPLA3 polymorphisms and HCC}

Both rs430397 in GRP78 and rs738409 in PNPLA3 were significantly associated with HCC risk in this Sicilian ancestry cohort (Table 4). The association between rs430397 in GRP78 and HCC risk is best described by a dominant model (AA+AG vs. GG), $(\mathrm{p}=0.0095, \mathrm{OR}=1.81)$ whereas the association between rs738409 in PNPLA3 is 
Table 1: Characteristics of the healthy controls and HCC cases included in the genetic association study

\begin{tabular}{lcc}
\hline Variable & Controls $(\mathbf{n}=\mathbf{3 0 4})$ & HCC cases $(\mathbf{n}=\mathbf{1 7 0})$ \\
\hline Age at diagnosis $(y r)$ & $56.6 \pm 8.1$ & $70.2 \pm 8.0$ \\
Gender & $214(70.4)$ & $99(58.2)$ \\
Men & $90(29.6)$ & $71(41.8)$ \\
Women & & $144(84.7)$ \\
Aetiology of Liver Disease & & $10(5.9)$ \\
HCV & & $10(5.9)$ \\
Alcohol & & $9(5.3)$ \\
Cryptogenic & & $1(0.6)$ \\
HBV & & \\
Dysmetabolic syndrome & & \\
\hline
\end{tabular}

Data are mean $\pm 1 \mathrm{SD}$ or number $(\%)$

Abbreviations: HCV- hepatitis C virus; HBV- hepatitis B virus.

Table 2: Historical, clinical, laboratory, imaging and histological information used to diagnosis cirrhosis in the HCC cases

\begin{tabular}{lc}
\hline Variables used to diagnose cirrhosis & Cases (n=170) \\
\hline History and clinical findings & Affected/abnormal n (\%) \\
Variceal hemorrhage & $66(38.8)$ \\
Ascites & $44(25.9)$ \\
Hepatic encephalopathy & $10(5.9)$ \\
Laboratory investigations & $137(80.6)$ \\
Thrombocytopaenia* & $53(31.2)$ \\
Prolonged prothrombin time* & $13(7.6)$ \\
Hypoalbuminaemia* & $11(6.5)$ \\
Hyperbilirubinaemia* & $163(95.9)$ \\
Investigations including imaging & $8(4.7)$ \\
Ultrasound & $5(2.9)$ \\
CT-Scan & $20(11.8)$ \\
Endoscopy & $19)$ \\
Histology &
\end{tabular}

* Laboratory cut-off values: platelet count: $<150$ x 109/L, Prothrombin time $>40 \mathrm{sec}$, plasma albumin $<35 \mathrm{~g} / \mathrm{L}$, serum bilirubin $>1.2 \mathrm{mg} / \mathrm{dl}$.

best described by a recessive model ( $\mathrm{GG}$ vs. $\mathrm{CG}+\mathrm{CC}$ ), $\left(\mathrm{p}=6.28 \times 10^{-3}, \mathrm{OR}=2.56\right)$ (Table 5).

When the analyses were confined to cases with $\mathrm{HCC}$ related to chronic $\mathrm{HCV}$ infection there was no evidence of association between rs430397 in GRP78 and $\mathrm{HCC}$ risk (Table 5). Because the frequency of the rs430397: AA genotype in this stratified cohort was very low, an association test under a recessive model of inheritance (AA vs. AG+GG) could not be performed using logistic regression. In contrast, the magnitude of the association between rs738409 in PNPLA3 and HCC risk increased when confined to the HCV positive HCC cases $\left(p=2.41 \times 10^{-3}, O R=2.82\right)$ (Table 5). There was no evidence for an epistatic interaction between the two variants and $\mathrm{HCC}$ risk $\left(\mathrm{P}_{\text {asymptotic }}=0.8, \mathrm{OR}_{\text {interaction }}=1.08\right)$. None of the demographic, clinical, laboratory or diagnostic variables was associated with either the GRP78 or PNPLA3 genotypes (Table 6). 
Table 3: Laboratory, imaging and histological information used to diagnose HCC

\begin{tabular}{lc}
\hline Variables used to diagnose cirrhosis & Cases $(\mathbf{n}=\mathbf{1 7 0})$ \\
\hline Laboratory Investigations & Affected/abnormal n $(\%)$ \\
Elevated serum alpha-fetoprotein* & $37(21.8)$ \\
Imaging & $146(85.9)$ \\
CT-Scan & $27(15.9)$ \\
Ultrasound & $27(15.9)$ \\
MRI-Scan & $20(11.8)$ \\
Histology & 20 \\
\hline
\end{tabular}

* Laboratory cut-off values: serum alpha-fetoprotein $>400 \mathrm{ng} / \mathrm{ml}$.

Table 4: Allelic associations between the SNPs rs430397 and rs738409 in sicilian cases with HCC and healthy controls

\begin{tabular}{|c|c|c|c|c|c|c|c|c|c|}
\hline \multirow{2}{*}{ Gene (SNP) } & \multirow{2}{*}{ Group } & \multirow{2}{*}{$\mathbf{n}$} & \multirow{2}{*}{ Minor Allele } & \multicolumn{3}{|c|}{ Genotype Counts } & \multirow{2}{*}{ MAF } & \multicolumn{2}{|c|}{ Cases vs Controls } \\
\hline & & & & & & & & Significance $p$ & OR $(95 \% \mathrm{CI})$ \\
\hline \multirow{4}{*}{$\begin{array}{l}\text { GRP78 } \\
\text { (rs430397) }\end{array}$} & & & \multirow{4}{*}{ A } & $\mathbf{A A}$ & $\mathbf{A G}$ & GG & & \multirow{4}{*}{0.016} & \multirow{4}{*}{$\begin{array}{c}1.65 \\
(1.09-2.50)\end{array}$} \\
\hline & Cases & 170 & & 1 & 46 & 123 & 0.141 & & \\
\hline & Controls & 304 & & 2 & 51 & 251 & 0.090 & & \\
\hline & & & & GG & $\mathrm{CG}$ & $\mathrm{CC}$ & & & \\
\hline \multirow{2}{*}{$\begin{array}{l}\text { PNPLA3 } \\
\text { (rs738409) }\end{array}$} & Cases & 170 & \multirow{2}{*}{ G } & 35 & 64 & 71 & 0.39 & \multirow{2}{*}{$4.22 \times 10^{-3}$} & \multirow{2}{*}{$\begin{array}{c}1.50 \\
(1.14-1.98)\end{array}$} \\
\hline & Controls & 304 & & 28 & 128 & 148 & 0.30 & & \\
\hline
\end{tabular}

Abbreviations: SNP - Single nucleotide polymorphism; n - number; MAF - Minor allele frequency; OR: Odds ratio; CI: Confidence Interval.

Table 5: Associations between rs430397 and rs738409 genotypes in sicilian cases with HCC and healthy controls using different genetic models

\begin{tabular}{|c|c|c|c|c|c|c|c|}
\hline \multirow[t]{2}{*}{ Gene (SNP) } & \multirow[t]{2}{*}{ Model } & \multicolumn{3}{|c|}{ Entire cohort $(n=474)$} & \multicolumn{3}{|c|}{$\begin{array}{l}\text { Entire cohort excluding non } \\
\text { HCV-related cases }(n=448)\end{array}$} \\
\hline & & $P$ & OR & $95 \%$ CI & $P$ & OR & $95 \%$ CI \\
\hline \multirow{3}{*}{$\begin{array}{l}G R P 78 \\
\text { (rs430397) }\end{array}$} & Allelic & 0.014 & 1.71 & $1.11-2.63$ & 0.0348 & 1.64 & $1.04-2.58$ \\
\hline & Dominant & 0.0095 & 1.81 & $1.16-2.83$ & 0.0190 & 1.76 & $1.10-2.82$ \\
\hline & Recessive & 0.93 & 0.89 & $0.08-9.93$ & - & - & - \\
\hline \multirow{3}{*}{$\begin{array}{l}\text { PNPLA3 } \\
\text { (rs738409) }\end{array}$} & Allelic & 0.0065 & 1.45 & $1.11-1.90$ & 0.00363 & 1.52 & $1.15-2.02$ \\
\hline & Dominant & 0.15 & 1.32 & $0.91-1.93$ & 0.127 & 1.37 & $0.92-2.04$ \\
\hline & Recessive & 0.0063 & 2.56 & $1.49-4.38$ & $2.41 \times 10^{-3}$ & 2.82 & $1.62-4.90$ \\
\hline
\end{tabular}

Abbreviations: SNP - Single nucleotide polymorphism; OR: Odds ratio; CI: Confidence Interval. 
Table 6: Association between rs430397 and rs738409 and demographic, clinical and laboratory variables in the HCC cases

\begin{tabular}{|c|c|c|c|c|c|c|c|c|}
\hline \multirow[b]{2}{*}{ Characteristics } & \multicolumn{3}{|c|}{ rs430397 } & \multicolumn{5}{|c|}{ rs738409 } \\
\hline & $\begin{array}{c}\mathbf{A} / \mathbf{A}+\mathbf{G} / \mathbf{A} \\
(n=47)\end{array}$ & $\begin{array}{c}G / G \\
(n=123)\end{array}$ & $p$ & $C / C(n=71)$ & $C / G(n=64)$ & $\begin{array}{c}G / G \\
(n=35)\end{array}$ & $\begin{array}{c}p \\
(C / C \text { vs } \\
C / G)\end{array}$ & $\begin{array}{c}p \\
(C / C \text { vs } \\
G / G)\end{array}$ \\
\hline \multicolumn{9}{|l|}{ Age (years): } \\
\hline$<71$ & $21(44.7 \%)$ & $59(48 \%)$ & & $35(49.3 \%)$ & $31(48.4 \%)$ & $14(40 \%)$ & 0.942 & 0.4867 \\
\hline$>=71$ & $26(55.3 \%)$ & $64(52 \%)$ & 0.832 & $36(50.7 \%)$ & $33(51.6 \%)$ & $21(60 \%)$ & & \\
\hline \multicolumn{9}{|l|}{ Gender: } \\
\hline M & $23(48.9 \%)$ & $76(61.8 \%)$ & & $44(62 \%)$ & $38(59.4 \%)$ & $17(48.6 \%)$ & 0.895 & 0.270 \\
\hline $\mathrm{F}$ & $24(51.1 \%)$ & $47(38.2 \%)$ & 0.178 & $27(38 \%)$ & $26(40.6 \%)$ & $18(51.4 \%)$ & & \\
\hline \multicolumn{9}{|l|}{$\mathrm{HCV}:$} \\
\hline Yes & $39(83 \%)$ & $105(85.4 \%)$ & & $59(83.1 \%)$ & $53(82.8 \%)$ & $32(91.4 \%)$ & 0.853 & 0.389 \\
\hline No & $8(17 \%)$ & $18(14.6 \%)$ & 0.882 & $12(16.9 \%)$ & $11(17.2 \%)$ & $3(8.6 \%)$ & & \\
\hline \multicolumn{9}{|l|}{ HBV: } \\
\hline Yes & $3(6.4 \%)$ & $6(4.9 \%)$ & & $5(7 \%)$ & $3(4.7 \%)$ & $1(2.9 \%)$ & 0.831 & 0.667 \\
\hline No & $44(93.6 \%)$ & $117(95.1 \%)$ & 0.993 & $66(93 \%)$ & $61(95.3 \%)$ & $34(97.1 \%)$ & & \\
\hline \multicolumn{9}{|l|}{ Alcohol: } \\
\hline Yes & $3(6.4 \%)$ & $7(5.7 \%)$ & & $4(5.6 \%)$ & $6(9.4 \%)$ & $0(0 \%)$ & 0.617 & 0.374 \\
\hline No & $44(27.5 \%)$ & $116(94.3 \%)$ & 0.847 & $67(94.4 \%)$ & $58(90.6 \%)$ & $35(100 \%)$ & & \\
\hline \multicolumn{9}{|l|}{ Cirrhosis: } \\
\hline Yes & $47(100 \%)$ & $122(99.2 \%)$ & & $71(100 \%)$ & $64(100 \%)$ & $34(97.1 \%)$ & 0.606 & 0.717 \\
\hline No & $0(0 \%)$ & $1(0.8 \%)$ & 0.616 & $0(0 \%)$ & $0(0 \%)$ & $1(2.9 \%)$ & & \\
\hline \multicolumn{9}{|l|}{ Cryptogenic: } \\
\hline Yes & $4(8.5 \%)$ & $6(4.9 \%)$ & & $4(5.6 \%)$ & $4(6.2 \%)$ & $2(5.7 \%)$ & 0.831 & 0.667 \\
\hline No & $43(91.5 \%)$ & $117(95.1 \%)$ & 0.592 & $67(94.4 \%)$ & $60(93.7 \%)$ & $33(94.3 \%)$ & & \\
\hline \multicolumn{9}{|l|}{ Dysmetabolic: } \\
\hline Yes & $0(0 \%)$ & $1(0.8 \%)$ & & $0(0 \%)$ & $1(1.6 \%)$ & $0(0 \%)$ & 0.958 & $7.00 \times 10^{-3}$ \\
\hline No & $47(100 \%)$ & $122(99.2 \%)$ & 0.616 & $71(100 \%)$ & $63(98.4 \%)$ & $35(100 \%)$ & & \\
\hline \multicolumn{9}{|l|}{ Ascites: } \\
\hline Yes & $11(23.4 \%)$ & $33(26.8 \%)$ & & $22(31 \%)$ & $12(18.8 \%)$ & $10(28.6 \%)$ & 0.958 & 0.976 \\
\hline No & $36(76.6 \%)$ & $90(73.2 \%)$ & 0.795 & $49(69 \%)$ & $52(81.2 \%)$ & $25(71.4 \%)$ & & \\
\hline \multicolumn{9}{|c|}{ Variceal hemorrhage: } \\
\hline Yes & $16(34 \%)$ & $50(40.7 \%)$ & & $28(39.4 \%)$ & $19(29.7 \%)$ & $19(54.3 \%)$ & 0.314 & 0.215 \\
\hline No & $31(66 \%)$ & $73(59.3 \%)$ & 0.539 & $43(60.6 \%)$ & $45(70.3 \%)$ & $16(45.7 \%)$ & & \\
\hline \multicolumn{9}{|c|}{ Hepatic encephalopathy: } \\
\hline Yes & $1(2.1 \%)$ & $9(7.3 \%)$ & & $6(8.5 \%)$ & $2(3.1 \%)$ & $2(5.7 \%)$ & 0.345 & 0.912 \\
\hline No & $46(97.9 \%)$ & $114(92.7 \%)$ & 0.357 & $65(91.5 \%)$ & $62(96.9 \%)$ & $33(94.3 \%)$ & & \\
\hline
\end{tabular}

(Continued) 


\begin{tabular}{|c|c|c|c|c|c|c|c|c|}
\hline \multirow[b]{2}{*}{ Characteristics } & \multicolumn{3}{|c|}{ rs430397 } & \multicolumn{5}{|c|}{ rs738409 } \\
\hline & $\begin{array}{c}\mathbf{A} / \mathbf{A}+\mathbf{G} / \mathbf{A} \\
(\mathrm{n}=\mathbf{4 7})\end{array}$ & $\begin{array}{c}\mathbf{G} / \mathbf{G} \\
(\mathrm{n}=123)\end{array}$ & $p$ & $C / C(n=71)$ & $C / G(n=64)$ & $\begin{array}{c}\text { G/G } \\
(n=35)\end{array}$ & $\begin{array}{c}p \\
(C / C \text { vs } \\
\text { C/G) }\end{array}$ & $\begin{array}{c}p \\
(C / C \text { vs } \\
\text { G/G) }\end{array}$ \\
\hline \multicolumn{9}{|c|}{ Thrombocytopaenia: } \\
\hline Yes & $42(89.4 \%)$ & $95(77.2 \%)$ & & $55(77.5 \%)$ & $52(81.5 \%)$ & $30(85.7 \%)$ & 0.742 & 0.458 \\
\hline No & $5(10.6 \%)$ & $28(22.8 \%)$ & 0.116 & $16(22.5 \%)$ & $12(18.8 \%)$ & $5(14.3 \%)$ & & \\
\hline \multicolumn{9}{|c|}{$\begin{array}{l}\text { Prolonged prothrombin } \\
\text { time }\end{array}$} \\
\hline Yes & $16(34 \%)$ & $37(30.1 \%)$ & & $23(32.4 \%)$ & $20(31.2 \%)$ & $10(28.6 \%)$ & 0.966 & 0.860 \\
\hline No & $31(66 \%)$ & $86(69.9 \%)$ & 0.754 & $48(67.6 \%)$ & $44(68.7 \%)$ & $25(71.4 \%)$ & & \\
\hline \multicolumn{9}{|c|}{ Hyperbilirubinaemia } \\
\hline Yes & $5(10.6 \%)$ & $6(4.9 \%)$ & & $3(4.2 \%)$ & $5(7.8 \%)$ & $3(8.6 \%)$ & 0.606 & 0.643 \\
\hline No & $42(89.4 \%)$ & $117(95.1 \%)$ & 0.309 & $68(95.8 \%)$ & $59(92.2 \%)$ & $32(91.4 \%)$ & & \\
\hline \multicolumn{9}{|c|}{ Hypoalbuminaemia } \\
\hline Yes & $4(8.4 \%)$ & $9(7.3 \%)$ & & $4(5.6 \%)$ & $7(10.9 \%)$ & $2(5.7 \%)$ & 0.418 & 0.667 \\
\hline No & $43(91.5 \%)$ & $114(92.7 \%)$ & 0.952 & $67(94.4 \%)$ & $57(89.1 \%)$ & $33(94.3 \%)$ & & \\
\hline \multicolumn{9}{|l|}{$\begin{array}{l}\text { Raised serum } \\
\text { alphafetoprotein }\end{array}$} \\
\hline Yes & $8(17 \%)$ & $29(23.6 \%)$ & 0.472 & $16(22.5 \%)$ & $16(25 \%)$ & $5(14.3 \%)$ & 0.894 & 0.458 \\
\hline No & $39(83 \%)$ & $94(76.4 \%)$ & & $55(77.5 \%)$ & $48(75 \%)$ & $30(85.7 \%)$ & & \\
\hline
\end{tabular}

\section{Modelling of phenotypes and PNPLA3/GRP78 polymorphisms in the $\mathrm{HCC}$ cases}

The first decision tree included different combinations of rs430397 and rs738409 genotypes, and the attributes of: age, sex, HCV status, ascites, variceal haemorrhage, prolonged prothrombin time and elevated serum alpha-fetoprotein (Figure 1). This decision tree had a misclassification rate (MCR) of $40 \%$.

The second decision tree included only three possible genotypic combinations: the rs $430397 \mathrm{G} / \mathrm{G}$ was fixed and combined with the three rs 738409 genotypes; the discriminating attributes were age, sex, HBV status, steatosis, ascites, variceal haemorrhage, thrombocytopenia, prolonged prothrombin time, elevated serum alphafetoprotein (Figure 2). The predictive power of this decision tree substantially improved resulting in a MCR of $24.4 \%$.

The third decision tree, which was complimentary to the second, kept only A/A and G/A genotypes of the rs430397 variant and the discriminating attributes: age, sex and alcohol. This was the most discriminating of the decision trees with a MCR of $17.0 \%$ (Figure 3).

\section{DISCUSSION}

The high variability of HCC incidence worldwide undoubtedly relates to differences in the distribution of environmental risk factors and most likely to variations in genetic susceptibilities between ethnic groups [24]. Outcomes in patients with HCC are critically dependent on early detection and diagnosis and hence the efficacy of public health strategies and screening programs [5]. The success of these programs, in turn, depends on the availability of validated, predictive markers with high sensitivity and specificity.

In the present study, two SNPs, rs430397 in GRP78 and rs738409 in PNPLA3, were shown to be significantly associated with the risk of developing HCC in a Sicilian population. Further the possibility that these risk-associated genetic variants could be used to prediction the development of $\mathrm{HCC}$ on an individual patient basis was explored, using a machine learning technique, with promising results.

Rs430397 lies in the fifth intron of GRP78. It has been associated with HCC risk in Chinese with HBV infection $[10,11]$ but does not appear to have been studied in European populations previously. As a non-proteincoding SNP, it could influence gene/protein function by altering gene expression but there is no direct evidence, to date, that this variant has functional effects. However, it does not lie in a GRP78 gene region associated with high transcriptional activity [25] nor in a $\mathrm{CpG}$ island associated with epigenetic mechanisms of gene silencing (T. Mazza: personal communication October 2016).

Physiologically the GRP78 protein acts as a molecular chaperone, which is activated by endoplasmic reticulum stress [26] and is involved in intracellular 


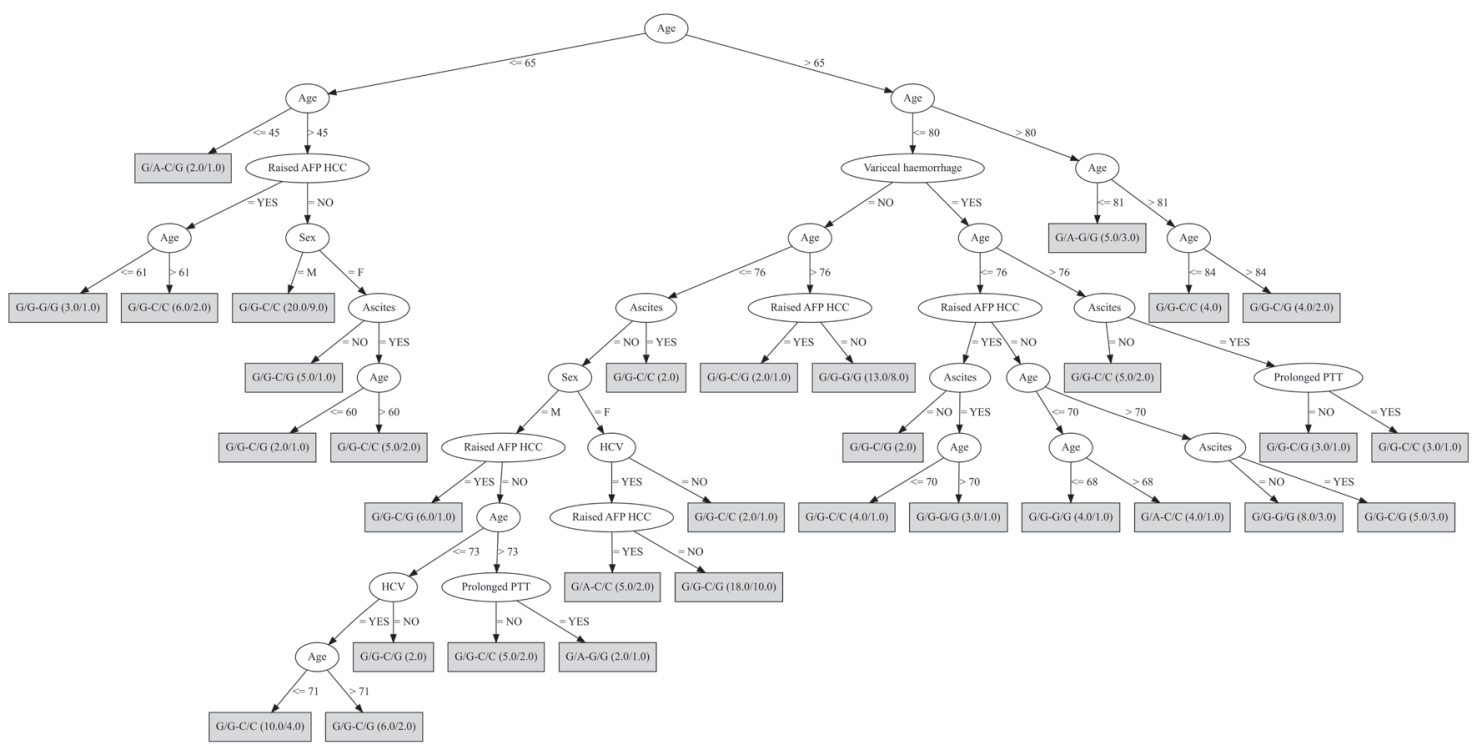

Figure 1: Decision tree based on the genotypes of both PNPLA3 and GRP78 SNPs. In this analysis the included discriminating attributes were: age, sex, HCV status, ascites, variceal haemorrhage, prolonged prothrombin time (PTT), elevated serum alpha-fetoprotein (AFP). The first genotype refers to the rs430397 variant and the second, separated by "-", refers to the rs738409 variant. The ratio of the genotypes accurately classified over those wrongly classified is provided for each genotype in brackets.

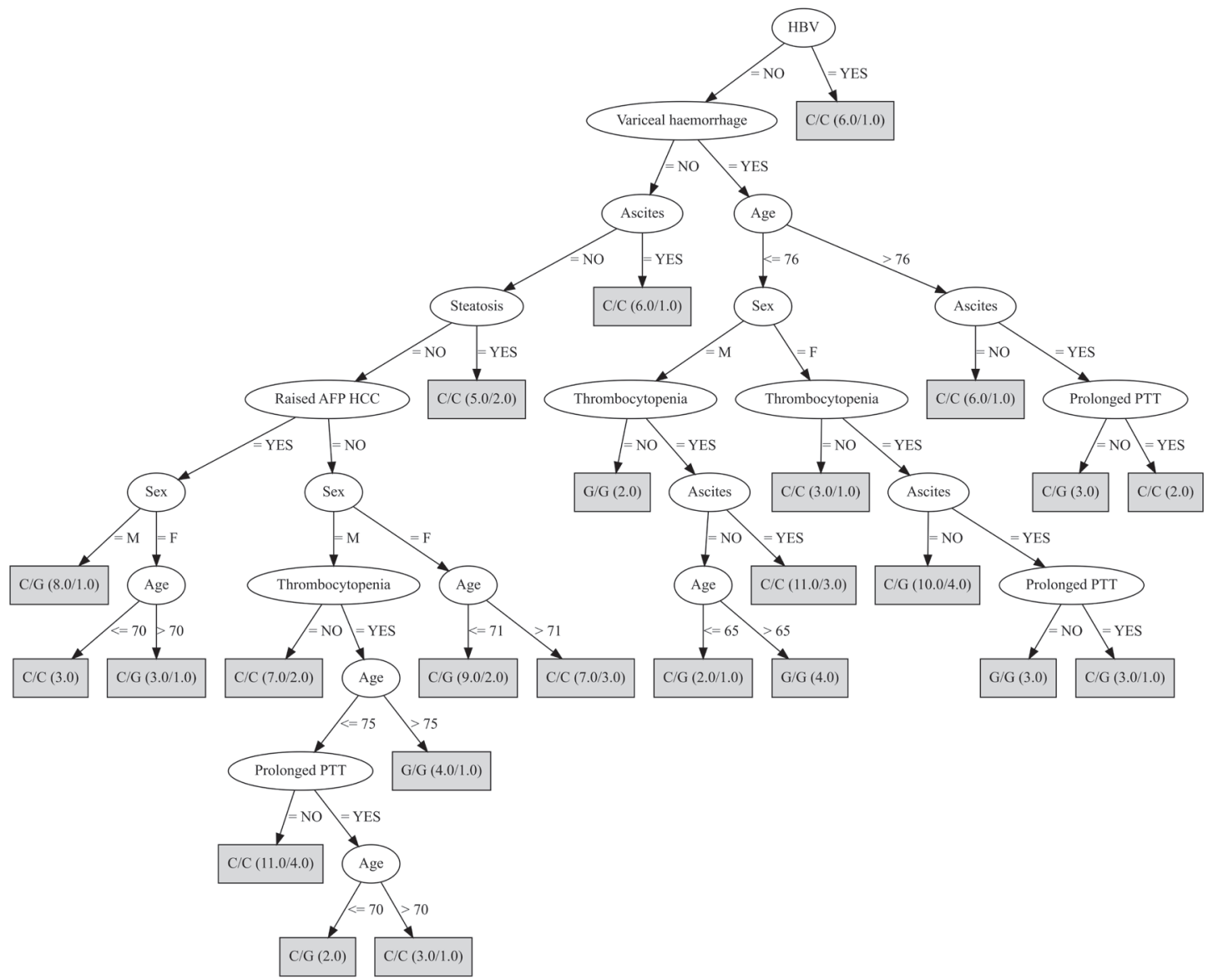

Figure 2: Decision tree developed fixing the $\mathbf{r s 4 3 0 3 9 7 ~ G / G ~ g e n o t y p e . ~ I n ~ t h i s ~ a n a l y s i s , ~ t h e ~ m o s t ~ d i s c r i m i n a t i n g ~ a t t r i b u t e s ~ w e r e : ~}$ age, sex, HBV, steatosis, ascites, variceal haemorrhage, thrombocytopenia, prolonged prothrombin time (PTT), elevated serum alphafetoprotein (AFP). The genotype in the box refers to rs 738409. The ratio of the genotypes accurately classified over those wrongly classified is provided for each genotype in brackets. 
calcium ion homeostasis [27]. It has also been reported to sustain cell survival, to inhibit apoptosis and to promote the invasion and metastasis of HCC cells in vitro [28-31]. However, the precise role of GRP78 in the development of cancer is still not clear [32, 33].

Rs738409 lies in the third exon of PNPLA3 and encodes a nonsynonymous alteration in the protein sequence (Ile148Met). This SNP came to prominence when identified as a risk factor for the progression of nonalcohol related fatty liver disease [16] and the development of alcohol-related cirrhosis [17]. Subsequently, the risk allele of rs738409 was shown to be associated with the development of HCC in patients of European descent with established cirrhosis [20]. Rs738409 has also been associated with the development of HCC in East Asian populations [34, 35]. The risk allele of rs738409 has also been studied in relation to HCV-related liver injury, although associations are less consistent [36, 37]. The results of the present study show that the rs738409:G allele is a significant risk for $\mathrm{HCC}$ in the Sicilian population. The fact that the strength of the association was increased in the subgroup with HCV-related cirrhosis with an effect size that exceeds that in many other studies is of interest but has to be weighed against the fact that these individuals comprised almost $85 \%$ of the study population.

Despite the substantial genetic evidence implicating rs 738409 and PNPLA3 with cirrhosis and HCC of different aetiologies, the function of the PNPLA3 protein remains uncertain as does the effect of the Ile148Met substitution. The 148Met risk allele appears to promote intracellular triglyceride retention [38] but the functional changes that lead to the development of significant liver damage and $\mathrm{HCC}$ remain to be established. Of interest the association between rs 738409 and liver disease progression appears to be independent of the severity of liver fat accumulation $[20,39]$. Further, the functional effects of this variant may directly or indirectly regulate the release of molecules

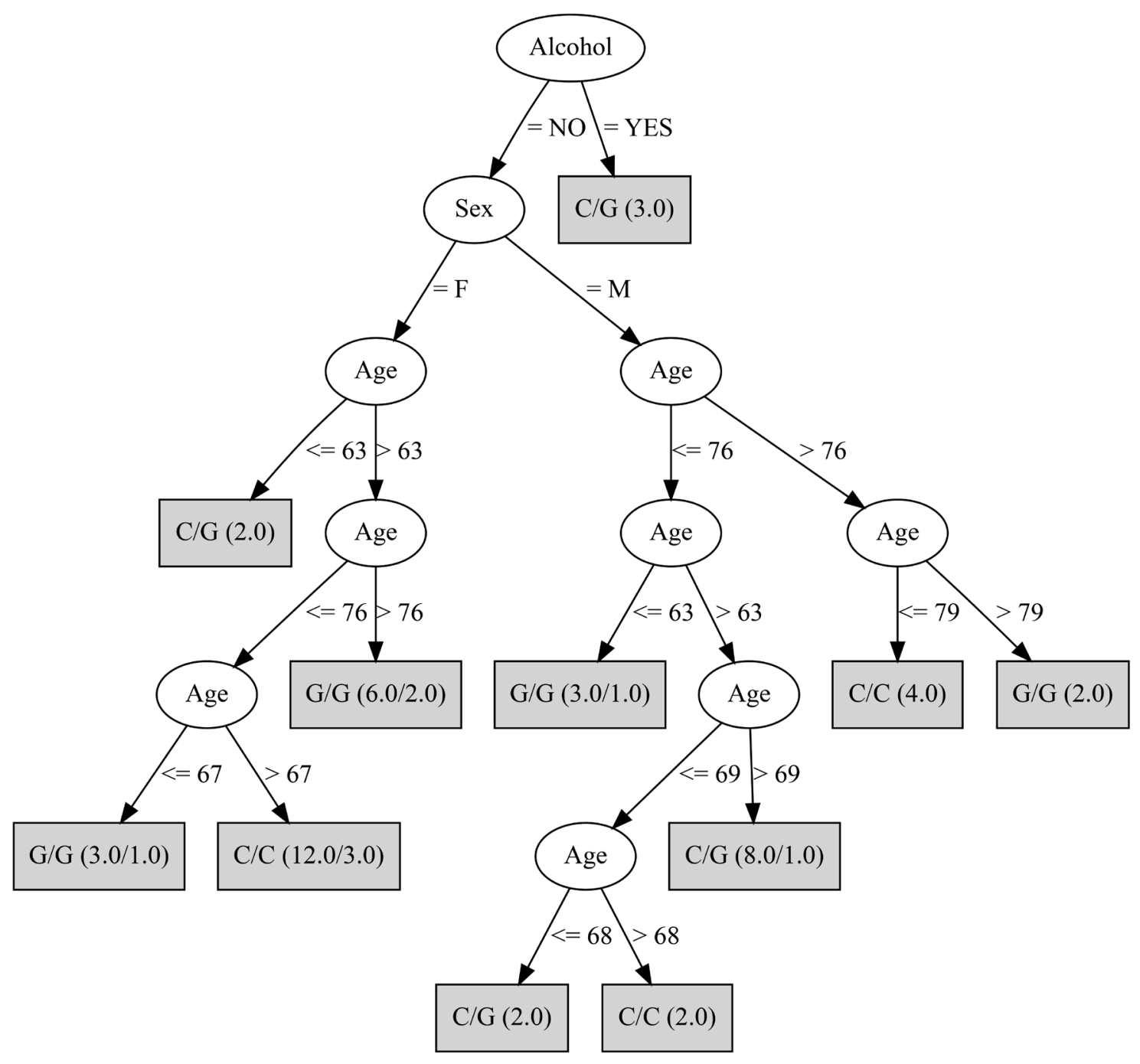

Figure 3: Decision tree developed fixing the rs430397 A/A and G/A genotypes. This analysis selected the age, sex and alcohol variables. The genotype in the box refers to the rs 738409 SNP. The ratio of the genotypes accurately classified over those wrongly classified is provided for each genotype in brackets. 
involved in inflammation and fibrogenesis as intercellular adhesion molecule 1 and adiponectin [40-43].

The MAF of the rs738409 variant in the Sicilian control population utilized in the present study was higher than expected when compared with an ancestrally appropriate European reference population, e.g. the Toscani from Italy [23] (30\% cf. 23\%). This difference in allele frequency could reflect genetic isolation of the population of Sicily. However, a recent study has shown that Sicilians are genetically similar to mainland Italians from the adjacent regions [44]. Another potential explanation for this observation could be cryptic underlying population stratification, which may have arisen due to the use of blooddonor controls. Despite this, similar blood-donor controls are used in the Wellcome Trust Case-Control consortium cohort [45] with little evidence to suggest significant population stratification in their analyses.

There was no evidence, in the present study, of an epistatic interaction between the GRP78 and PNPLA3 variants in relation to $\mathrm{HCC}$ risk. In addition there were no significant associations between either variant and any clinical features or the results of any of the laboratory investigation. However, combinations of these various attributes together with the rs430397 and rs738409 genotypes were used to produce a model, graphically displayed as a decision tree, which could be useful for predicting subjects at risk for developing $\mathrm{HCC}$, at least within this study population. The best prediction model used only age, sex and alcohol as the additional required variables and was represented by a decision tree with a MCR of $17.0 \%$.

In conclusion: rs430397 in GRP78 and rs738409 in PNPLA3 are risk factors for the development of HCC in a Southern Italian population of cases with predominantly HCV-related cirrhosis. Use of a machine-learning approach allowed development of a prediction model incorporating phenotypic, clinical and genotypic variables. This computational approach needs to be further explored and the predictions independently validated. If confirmed, this approach could be used to identify individuals at risk at an early stage thereby facilitating monitoring and, when required, early intervention.

\section{PATIENTS AND METHODS}

\section{Study populations}

The 170 HCC cases were enrolled at the Department of Internal Medicine and Medical Specialties of the Policlinico Hospital, Palermo, Italy. All had been born in Sicily and continued to reside there. The aetiology of the liver disease was determined using historical, clinical, laboratory, imaging and histological information. The diagnosis of cirrhosis and HCC were made based on previously reported criteria [46], and international guidelines [47]. In the majority of instances the diagnosis of cirrhosis was based on historical, clinical, laboratory and radiological variables; histological confirmation was available in a minority from liver biopsy material obtained via the percutaneous route (Table 2). The diagnosis of HCC was based on historical, clinical, and laboratory variables together with, as recommended, multimodal imaging (Table 3). The 304 healthy blood donors, who acted as controls, were recruited at the Azienda di Rilievo Nazionale ad Alta Specialiazzione (A.R.N.A.S.) Civico Hospital of Palermo, Italy. Controls were only included if they were born in and continued to reside in Sicily; were aged $>30$ years and in line with International guidelines $[48,49]$ were negative for $\mathrm{HBsAg}$, anti-HCV and anti HIV antibodies and had normal routine blood test results.

All included cases and controls provided written informed consent. This research was approved by the Ethics committee of the Policlinico Hospital (Palermo, Italy).

\section{DNA extraction and genotyping}

Genomic DNA was extracted from whole blood using the WizardGenomic DNA Purification Kit (Promega). DNA quality was assessed using gel electrophoresis $(0.8 \%$ agarose gel; 5 volts $/ \mathrm{cm}$ for 1 hour; $1 \times$ Tris-borate-EDTA (TBE) buffer; $100 \mathrm{bp}$ and $1 \mathrm{~kb}$ DNA Ladder (Promega, UK). Genotyping for rs430397 in GRP78 and rs738409 in PNPLA3 was performed using the K-Biosciences Competitive Allele Specific PCR (LGC Genomics, Hoddesdon, UK) platform with amplification and detection undertaken using a LightCycler ${ }^{\circledR} 480$ realtime PCR system (Roche Molecular Diagnostics, Burgess Hill, UK). Genotype calling was performed automatically using proprietary software with minor manual editing of genotype calls. Approximately $12 \%$ of samples, randomly selected a priori, were genotyped in duplicate to ensure consistent genotype calling. The primers used for KASPar genotyping are detailed in Supplementary Table 1.

\section{Statistical analysis}

\section{Genetic analysis}

Tests for genetic association, missingness, deviation from Hardy-Weinberg equilibrium and epistasis were performed using PLINK (version 1.9) [50]. Genetic association analyses were performed using logistic regression utilizing additive, dominant and recessive models when comparing HCC cases and controls. Tests for association between demographic covariates were performed under an additive model using the Fisher's exact test to assess significance. Statistical analyses were performed in $\mathrm{R}$ [51].

\section{Prediction modelling}

A two-step analysis comprising of variable selection and decision tree construction was performed 
using a machine learning technique to establish a rule for predicting phenotypes starting from the genotypes of both the rs430397 and rs 738409 variants. In the first step the variables to be used in the second step were selected utilizing a stepwise search, which performs a greedy forward or backward search through the space of HCC case characteristics or attributes. The selection is based on a decision tree classifier for estimating the accuracy of the chosen variable subset and is stopped when the addition/ deletion of any remaining attribute resulted in a decrease in evaluation. The second step involved the construction of a tree-like graph or model of decisions based on the previously selected variables. This model exhibits a flowchart-like structure in which each internal node represents a 'test' on an attribute, each branch represents the outcome of the test and each leaf node represents a class label. The paths from root to leaves represent the classification rules. The evaluation of the classifier is based on the overall misclassification rate (MCR); the lower the MCR the better the prediction modelling. Both steps were performed using the RWeka package (R-3.2.3 software).

\section{CONFLICTS OF INTEREST}

None of the authors declare a conflicts of interest.

\section{GRANT SUPPORT}

MV is supported by a My First Associazione Italiana Ricerca sul Cancro (AIRC) Grant-AIRC Grant No.13419, by UCL and by grants No. LQ1605 (MEYS CR) and FNUSA-ICRC No. CZ.1.05/1.1.00/02.0123 (OP VaVpI).

\section{REFERENCES}

1. El-Serag HB, Rudolph KL. Hepatocellular carcinoma: epidemiology and molecular carcinogenesis. Gastroenterology. 2007; 132:2557-2576.

2. Lafaro KJ, Demirjian AN, Pawlik TM. Epidemiology of hepatocellular carcinoma. Surg Oncol Clin N Am. 2015; 24:1-17.

3. Bosetti C, Turati F, La Vecchia C. Hepatocellular carcinoma epidemiology. Best Pract Res Clin Gastroenterol. 2014; 28:753-770.

4. Liu Y, Wu F. Global burden of aflatoxin-induced hepatocellular carcinoma: a risk assessment. Environ Health Perspect. 2010; 118:818-824.

5. Singal AG, El-Serag HB. Hepatocellular Carcinoma From Epidemiology to Prevention: Translating Knowledge into Practice. Clin Gastroenterol Hepatol. 2015; 13:2140-2151.

6. Venook AP, Papandreou C, Furuse J, de Guevara LL. The incidence and epidemiology of hepatocellular carcinoma: a global and regional perspective. Oncologist. 2010; 15 Suppl 4:5-13.

7. El-Serag HB. Epidemiology of viral hepatitis and hepatocellular carcinoma. Gastroenterology. 2012; 142:1264-1273.e1261.

8. Huang X, Hollinger FB. Occult hepatitis B virus infection and hepatocellular carcinoma: a systematic review. J Viral Hepat. 2014; 21:153-162.

9. Donato F, Gelatti U, Limina RM, Fattovich G. Southern Europe as an example of interaction between various environmental factors: a systematic review of the epidemiologic evidence. Oncogene. 2006; 25:3756-3770.

10. Zhu X, Chen MS, Tian LW, Li DP, Xu PL, Lin MC, Xie D, Kung HF. Single nucleotide polymorphism of rs430397 in the fifth intron of GRP78 gene and clinical relevance of primary hepatocellular carcinoma in Han Chinese: risk and prognosis. Int J Cancer. 2009; 125:1352-1357.

11. Zhu X, Chen L, Fan W, Lin MC, Tian L, Wang M, Lin S, Wang Z, Zhang J, Wang J, Yao H, Kung H, Li D. An intronic variant in the GRP78, a stress-associated gene, improves prediction for liver cirrhosis in persistent HBV carriers. PLoS One. 2011; 6:e21997.

12. Zhang XX, Li HD, Zhao S, Zhao L, Song HJ, Wang G, Guo QJ, Luan ZD, Su RJ. The cell surface GRP78 facilitates the invasion of hepatocellular carcinoma cells. Biomed Res Int. 2013; 2013:917296.

13. Lee AS. Glucose-regulated proteins in cancer: molecular mechanisms and therapeutic potential. Nat Rev Cancer. 2014; 14:263-276.

14. Zhang D, Zhou B, Li Y, Wang M, Wang C, Zhou Z, Sun X. Polymorphisms of glucose-regulated protein 78 and risk of colorectal cancer: a case-control study in southwest China. PLoS One. 2013; 8:e66791.

15. Zhu X, Lin MC, Fan W, Tian L, Wang J, Ng SS, Wang M, Kung H, Li D. An intronic polymorphism in GRP78 improves chemotherapeutic prediction in non-small cell lung cancer. Chest. 2012; 141:1466-1472.

16. Romeo S, Kozlitina J, Xing C, Pertsemlidis A, Cox D, Pennacchio LA, Boerwinkle E, Cohen JC, Hobbs HH. Genetic variation in PNPLA3 confers susceptibility to nonalcoholic fatty liver disease. Nat Genet. 2008; 40:1461-1465.

17. Buch S, Stickel F, Trepo E, Way M, Herrmann A, Nischalke HD, Brosch M, Rosendahl J, Berg T, Ridinger M, Rietschel M, McQuillin A, Frank J, et al. A genome-wide association study confirms PNPLA3 and identifies TM6SF2 and MBOAT7 as risk loci for alcohol-related cirrhosis. Nat Genet. 2015; 47:1443-1448.

18. Burza MA, Pirazzi C, Maglio C, Sjoholm K, Mancina RM, Svensson PA, Jacobson P, Adiels M, Baroni MG, Boren J, Ginanni Corradini S, Montalcini T, Sjostrom L, et al. PNPLA3 I148M (rs738409) genetic variant is associated with hepatocellular carcinoma in obese individuals. Dig Liver Dis. 2012; 44:1037-1041. 
19. Guyot E, Sutton A, Rufat P, Laguillier C, Mansouri A, Moreau R, Ganne-Carrie N, Beaugrand M, Charnaux N, Trinchet JC, Nahon P. PNPLA3 rs738409, hepatocellular carcinoma occurrence and risk model prediction in patients with cirrhosis. J Hepatol. 2013; 58:312-318.

20. Trepo E, Nahon P, Bontempi G, Valenti L, Falleti E, Nischalke HD, Hamza S, Corradini SG, Burza MA, Guyot E, Donati B, Spengler U, Hillon P, et al. Association between the PNPLA3 (rs738409 $\mathrm{C}>\mathrm{G}$ ) variant and hepatocellular carcinoma: Evidence from a metaanalysis of individual participant data. Hepatology. 2014; 59:2170-2177.

21. Yang HI, Yuen MF, Chan HL, Han KH, Chen PJ, Kim DY, Ahn SH, Chen CJ, Wong VW, Seto WK, Group R-BW. Risk estimation for hepatocellular carcinoma in chronic hepatitis $\mathrm{B}$ (REACH-B): development and validation of a predictive score. Lancet Oncol. 2011; 12:568-574.

22. Libbrecht MW, Noble WS. Machine learning applications in genetics and genomics. Nat Rev Genet. 2015; 16:321-332.

23. 1000 Genomes Project Consortium, Abecasis GR, Auton A, Brooks LD, DePristo MA, Durbin RM, Handsaker RE, Kang HM, Marth GT, McVean GA. An integrated map of genetic variation from 1,092 human genomes. Nature. 2012; 491:56-65.

24. Mittal S, El-Serag HB. Epidemiology of hepatocellular carcinoma: consider the population. J Clin Gastroenterol. 2013; 47 Suppl:S2-6.

25. Boyle AP, Hong EL, Hariharan M, Cheng Y, Schaub MA, Kasowski M, Karczewski KJ, Park J, Hitz BC, Weng S, Cherry JM, Snyder M. Annotation of functional variation in personal genomes using RegulomeDB. Genome research. 2012; 22:1790-1797.

26. Wang M, Wey S, Zhang Y, Ye R, Lee AS. Role of the unfolded protein response regulator GRP78/BiP in development, cancer, and neurological disorders. Antioxid Redox Signal. 2009; 11:2307-2316.

27. Hammadi M, Oulidi A, Gackiere F, Katsogiannou M, Slomianny C, Roudbaraki M, Dewailly E, Delcourt P, Lepage G, Lotteau S, Ducreux S, Prevarskaya N, Van Coppenolle F. Modulation of ER stress and apoptosis by endoplasmic reticulum calcium leak via translocon during unfolded protein response: involvement of GRP78. FASEB J. 2013; 27:1600-1609.

28. Zhao G, Kang J, Jiao K, Xu G, Yang L, Tang S, Zhang H, Wang Y, Nie Y, Wu K, Fan D, Zhang H, Zhang D. High Expression of GRP78 Promotes Invasion and Metastases in Patients with Esophageal Squamous Cell Carcinoma. Dig Dis Sci. 2015; 60:2690-2699.

29. Zhang LH, Zhang X. Roles of GRP78 in physiology and cancer. J Cell Biochem. 2010; 110:1299-1305.

30. Li Z, Wang Y, Wu H, Zhang L, Yang P, Li Z. GRP78 enhances the glutamine metabolism to support cell survival from glucose deficiency by modulating the beta-catenin signaling. Oncotarget. 2014; 5:5369-5380. doi: 10.18632/ oncotarget. 2105 .
31. Ying L, Zhu Z, Xu Z, He T, Li E, Guo Z, Liu F, Jiang C, Wang Q. Cancer Associated Fibroblast-Derived Hepatocyte Growth Factor Inhibits the Paclitaxel-Induced Apoptosis of Lung Cancer A549 Cells by Up-Regulating the PI3K/Akt and GRP78 Signaling on a Microfluidic Platform. PLoS One. 2015; 10:e0129593.

32. Dong D, Ni M, Li J, Xiong S, Ye W, Virrey JJ, Mao C, Ye R, Wang M, Pen L, Dubeau L, Groshen S, Hofman FM, et al. Critical role of the stress chaperone GRP78/BiP in tumor proliferation, survival, and tumor angiogenesis in transgeneinduced mammary tumor development. Cancer Res. 2008; 68:498-505.

33. Chang YJ, Chen WY, Huang CY, Liu HH, Wei PL. Glucoseregulated protein 78 (GRP78) regulates colon cancer metastasis through EMT biomarkers and the NRF-2/HO-1 pathway. Tumour Biol. 2015; 36:1859-1869.

34. Tomoda T, Nouso K, Sakai A, Ouchida M, Kobayashi S, Miyahara K, Onishi H, Nakamura S, Yamamoto K, Shimizu $\mathrm{K}$. Genetic risk of hepatocellular carcinoma in patients with hepatitis C virus: a case control study. J Gastroenterol Hepatol. 2012; 27:797-804.

35. Moritou Y, Ikeda F, Iwasaki Y, Baba N, Takaguchi K, Senoh T, Nagano T, Takeuchi Y, Yasunaka T, Ohnishi H, Miyake Y, Takaki A, Nouso K, et al. Predictive impact of polymorphism of PNPLA3 on HCC development after interferon therapy in Japanese patients with chronic hepatitis C. Springerplus. 2013; 2:251.

36. Cai T, Dufour JF, Muellhaupt B, Gerlach T, Heim M, Moradpour D, Cerny A, Malinverni R, Kaddai V, Bochud M, Negro F, Bochud PY, Swiss Hepatitis CCSG. Viral genotype-specific role of PNPLA3, PPARG, MTTP, and IL28B in hepatitis C virus-associated steatosis. J Hepatol. 2011; 55:529-535.

37. Nakaoka K, Hashimoto S, Kawabe N, Nitta Y, Murao M, Nakano T, Shimazaki H, Kan T, Takagawa Y, Ohki M, Kurashita T, Takamura T, Nishikawa T, et al. PNPLA3 I148M associations with liver carcinogenesis in Japanese chronic hepatitis C patients. Springerplus. 2015; 4:83.

38. Pirazzi C, Adiels M, Burza MA, Mancina RM, Levin M, Stahlman M, Taskinen MR, Orho-Melander M, Perman J, Pujia A, Andersson L, Maglio C, Montalcini T, et al. Patatin-like phospholipase domain-containing 3 (PNPLA3) I148M (rs738409) affects hepatic VLDL secretion in humans and in vitro. J Hepatol. 2012; 57:1276-1282.

39. Valenti L, Motta BM, Soardo G, Iavarone M, Donati B, Sangiovanni A, Carnelutti A, Dongiovanni P, Rametta R, Bertelli C, Facchetti F, Colombo M, Fargion S, et al. PNPLA3 I148M polymorphism, clinical presentation, and survival in patients with hepatocellular carcinoma. PLoS One. 2013; 8:e75982.

40. Pirazzi C, Valenti L, Motta BM, Pingitore P, Hedfalk K, Mancina RM, Burza MA, Indiveri C, Ferro Y, Montalcini T, Maglio C, Dongiovanni P, Fargion S, et al. PNPLA3 has retinyl-palmitate lipase activity in human hepatic stellate cells. Hum Mol Genet. 2014; 23:4077-4085. 
41. Paré G, Ridker PM, Rose L, Barbalic M, Dupuis J, Dehghan A, Bis JC, Benjamin EJ, Shiffman D, Parker AN. Genomewide association analysis of soluble ICAM-1 concentration reveals novel associations at the NFKBIK, PNPLA3, RELA, and SH2B3 loci. PLoS Genet. 2011; 7:e1001374.

42. Valenti L, Rametta R, Ruscica M, Dongiovanni P, Steffani L, Motta BM, Canavesi E, Fracanzani AL, Mozzi E, Roviaro G, Magni P, Fargion S. The I148M PNPLA3 polymorphism influences serum adiponectin in patients with fatty liver and healthy controls. BMC Gastroenterol. 2012; 12:111.

43. Marra F, Bertolani C. Adipokines in liver diseases. Hepatology. 2009; 50:957-969.

44. Sarno S, Boattini A, Carta M, Ferri G, Alu M, Yao DY, Ciani G, Pettener D, Luiselli D. An ancient Mediterranean melting pot: investigating the uniparental genetic structure and population history of sicily and southern Italy. PLoS One. 2014; 9:e96074.

45. Burton PR, Clayton DG, Cardon LR, Craddock N, Deloukas P, Duncanson A, Kwiatkowski DP, McCarthy MI, Ouwehand WH, Samani NJ, Todd JA, Donnelly P, Barrett JC, et al. Genome-wide association study of 14,000 cases of seven common diseases and 3,000 shared controls. Nature. 2007; 447:661-678.

46. Soresi M, La Spada E, Giannitrapani L, Campagna E, Di Gesaro V, Grana W, Sandonato L, Brancatelli G, Rotolo
G, Affronti A, Messina S, Montalto G. Hepatocellular carcinoma: comparison of two different periods at the same center. Eur J Intern Med. 2010; 21:127-130.

47. Bruix J, Sherman M, Llovet JM, Beaugrand M, Lencioni R, Burroughs AK, Christensen E, Pagliaro L, Colombo M, Rodes J, HCC EPoEo. Clinical management of hepatocellular carcinoma. Conclusions of the Barcelona-2000 EASL conference. European Association for the Study of the Liver. J Hepatol. 2001; 35:421-430.

48. World Health Organization. (2012). Blood Donor Selection: Guidelines on Assessing Donor Suitability for Blood Donation. (Geneva: World Health Organization.,).

49. THE COMMISSION OF THE EUROPEAN COMMUNITIES. COMMISSION DIRECTIVE 2004/33/

EC of 22 March 2004 implementing Directive 2002/98/

EC of the European Parliament and of the Council as regards certain technical requirements for blood and blood components. OJEU. 2004; 91:25-39.

50. Purcell S, Neale B, Todd-Brown K, Thomas L, Ferreira MA, Bender D, Maller J, Sklar P, de Bakker PI, Daly MJ, Sham PC. PLINK: a tool set for whole-genome association and population-based linkage analyses. Am J Hum Genet. 2007; 81:559-575.

51. R Core Team. (2014). R: A language and environment for statistical computing. R Foundation for Statistical Computing, Vienna, Austria. 2013. ISBN 3-900051-07-0). 